\title{
The most complex theory of the symmetric impact of the vibrating digging working tool on the sugar beet root
}

\author{
Volodymyr Bulgakov, ${ }^{1}$ Hristo Beloev, ${ }^{2}$ Ivan Holovach, ${ }^{1}$ Vladimír Kročko, ${ }^{3}$ Ladislav Nozdrovicky, ${ }^{3}$ \\ Pavol Findura ${ }^{3}$ \\ ${ }^{1}$ National University of Life and Environmental Sciences of Ukraine; ${ }^{2}$ Angel Kanchev University of Rousse, Bulgaria; \\ ${ }^{3}$ Slovak University of Agriculture in Nitra, Slovak Republic
}

\begin{abstract}
When digging sugar beet root out of the soil by using a vibration digging working tools, there occur impact contacts of the working tools and sugar beet roots placed in the soil. Such phenomena are formed mainly in conditions of dry and solid soil. The consequence of this is a significant impact contact tails breaks, chips or damage of the side surfaces of roots, which leads ultimately to a non-return losses on sugar mass. Therefore there is a need to develop the basic provisions of the refined theory of impact interaction of a vibrating digging working tool with the body of the sugar beet root fixed in the soil, and on the basis of the results obtained to justify rational kinematic and structural parameters of advanced vibration digging working tool.

Within the research there was used the methods of higher mathematics, theoretical mechanics, programming and numerical calculations on the PC. We have developed a refined theory of impact interaction of digging of the working body of the sugar beet harvester with the body of sugar beet root during vibratory digging of sugar beet roots from the dry and solid soil. On the basis of obtained equations and their numerical solution by PC programme it was possible to define the kinematic and structural parameters of vibration digging working tool that will ensure the conditions not to damage or break the tails of the sugar beet roots during their digging out from the dry and solid soil. We have investigated the so-called symmetric impact of the vibrating dig-
\end{abstract}

Correspondence: Ladislav Nozdrovicky, Slovak University of Agriculture in Nitra, Tr. A. Hlinku 2, 949 76, Nitra, Slovak Republic. E-mail: ladislav.nozdrovicky@gmail.com

Key words: Sugar beet; sugar beet root; harvest; vibrations; digging working tool; impact impulse; vibration frequency; the equation of the impact interaction; design parameters.

Received for publication: 25 September 2017.

Accepted for publication: 4 May 2018.

(C) Copyright V. Bulgakov et al., 2018

Licensee PAGEPress, Italy

Journal of Agricultural Engineering 2018; XLIX:795

doi:10.4081/jae.2018.795

This article is distributed under the terms of the Creative Commons Attribution Noncommercial License (by-nc 4.0) which permits any noncommercial use, distribution, and reproduction in any medium, provided the original author(s) and source are credited. ging working body and the body of sugar beet root. As shown by calculations of the obtained theoretical dependencies and confirmed experimental studies, for the range of reduced masses of the vibrating excavating organ $0.8-2.0 \mathrm{~kg}$, the translational velocity $1.3-2.2 \mathrm{~m} \cdot \mathrm{s}^{-1}$, the depth in the soil $0.08-0.12 \mathrm{~m}$ and the vibration amplitude $0.008-0.024 \mathrm{~m}$ for shock interaction, which is most likely in dry and solid soil, the permissible oscillation frequency of scooping coulter is $10.0-18.0 \mathrm{~Hz}$.

\section{Problem formulation}

Currently, for the harvesting of sugar beet roots there are widely used vibration digging working tools, which are installed on sugar beet digging harvesters, produced in many countries around the world. Such method of the digging of the sugar beet root from the soil has several advantages compared with other methods, particularly in a dry and solid soil. Namely, when a vibrating digging is used there is achieved the most complete cleaning of the side surfaces of the sugar beet roots from adhering soil, as well as minimal damage of the sugar beet roots. In addition, due to the vibratory destruction of the soil surrounding the roots, there can be observed the intensive decreasing of the specific resistance of the forward movement of digging tools that finally results in lower energy requirements for the implementation of this technological process. Therefore, namely this technological process of harvesting of the sugar beet roots requires a more deep analytical research and further development in order to create more effective working tools for sugar beet digging. In relation to sugar beet harvesters as a main requirement can be considered the quality of the sugar beet roots from the soil without damage of the roots (cliffs on the root tails, slices, chips and heavy damage to the side surfaces) and losses (in the soil, in the form of broken and remaining there or tails on the their surface). It is obvious that the probability of the damage of the sugar beet roots and their losses exists, in the greatest extent, during the direct interaction of the digging working tools with the sugar beet roots located (actually fixed) in the soil. This is especially true for vibrating digging working tools, working in dry soil conditions during sugar beet harvest. Therefore there is a need for theoretical study of the interaction impact of the vibrating digging working tool and sugar beet root fixed in the soil and on the basis of the results obtained to determine the kinematic and design parameters of the improved working body that ensures the process of sugar beet roots digging from the soil without damage.

Therefore, there is analysed the initial impact contact interaction of the digging working tool and body of the sugar beet root and subsequent of its removing from the soil. Such approach can be considered as a most accurate and complex task in the area of mechanization of the sugar beet harvest. 


\section{Analysis of the latest research and publications}

Currently, there exist a number of publications presenting new results of theoretical and experimental investigation concerning the digging process of the sugar beet roots from the soil. So, fundamental theoretical investigations of the vibration process of digging of sugar beet roots from the soil are given in other papers (Vasilenko et al., 1970; Bulgakov and Golovach, 2004; Pogorelij and Tatjanko, 2004; Bulgakov et al., 2005; Bulgakov and Golovach, 2006a, 2006b; Golovach, 2006; Bulgakov and Ivanov, 2010; Ivanov et al., 2011; Bulgakov et al., 2015a).

Let's analyze some published works. So, in the article by Bulgakov and Ivanov (2010) the theory of direct extraction of sugar beet root from the soil during vibration digging is considered. An equivalent scheme for the interaction of the excavating working organ and the sugar beet root body has been made and a system of differential equations for moving of the sugar beet roots has been obtained, the solution of which has made it possible to determine the influence of the structural parameters of the working element and the kinematic regimes of the technological process during the extraction of roots from the soil, which significantly affects the productivity of the sugar beet roots harvesting machine. The results presented by Bulgakov and Ivanov (2010) were further developed by Ivanov et al. (2011), where a system of differential equations for the rotation of the beetroot during vibration excavation was compiled. In Bulgakov et al. (2015a), spatial fluctuations of sugar beet root in the soil as a solid with one fixed point are considered. On the basis of Euler dynamic and kinematic equations, a system of differential equations is obtained that describes this oscillatory process during vibrational excavation.

However, the analytical study of the impact interaction between the vibration digging working tool and sugar beet root, fixed in the soil root, there is not considered. Only in publications by Pogorelij and Tatjanko $(1983,2004)$ there are presented some experimental data obtained in the study of the interaction of a pendulum impact with the head of sugar beet root.

Published earlier theoretical studies of the impact interaction of vibrating digging working tool and sugar beet root in the symmetric and asymmetric of its capture are not sufficient to accurately reflect the full extent of the actual process, which occurs in such impact interaction (Bulgakov et al., 2015b, 2015c). Thus, in Bulgakov et al. (2015b) an attempt was made to construct a theory of the shock interaction of a vibratory excavating working organ with a sugar beet root, fixed in the soil, when the specified working organ hits it. On the basis of the theorem on the change in the amount of motion upon impact, a system of equations describing this shock contact was obtained, on the basis of which limitations were obtained on the permissible vibration frequency of the vibratory excavation-working organ from the condition of rooting integrity. However, the theory presented in this paper is not described in sufficient detail. Some important points of this theory have remained unexplained. In addition, the calculations were made only for several values of the kinematic and design parameters of the vibratory working element. Calculations for a wide range of masses of working organs, speeds of translational motion, vibration amplitudes, depths of the working organ in the soil, which make it possible to obtain a complete picture of the course of the impact contact, are not presented in this paper. In addition, in this paper, only one graph is presented, based on the calculation for only one set of the above parameters.

Similar shortcomings are also found in Bulgakov et al. (2015c, 2015d). Therefore, there is a need for a fairly complete and detailed presentation of all the stages of constructing the theory of this interaction, conducting a wide range of necessary calculations on a PC to determine the rational design and kinematic parameters of the vibratory excavating working organ from the conditions of intact sugar beet roots. There is also a need for experimental confirmation of the theoretical results obtained.

\section{Aim of the research}

To develop the basic provisions of the most complex theory of the impact interaction of vibration digging working tool with the body of the sugar beet root fixed in the soil, and on the basis of the results obtained to justify rational kinematic and design parameters of improved vibration digging working tools.

In general, the obtained results of analytical studies should be used for further improvement of the technological process of digging of sugar beet roots from the soil, based on the conditions not to damage the roots.

\section{Methods used in research}

For creating a most complex theory of symmetric impact of the vibration digging working tool and sugar beet root there were used the methods of higher mathematics, theoretical mechanics, in particular, the theory of vibrations and impact theory. Theoretical studies were carried out on the basis of the general theory of vibration digging of the sugar beet roots, presented in otherr papers (Vasilenko et al., 1970; Bulgakov and Golovach, 2002, 2004; Pogorelij and Tatjanko, 2004; Bulgakov et al., 2005; Bulgakov and Golovach, 2006a, 2006b; Golovach, 2006; Bulgakov and Ivanov, 2010; Ivanov et al., 2011; Adamchuk and Bulgakov, 2015). Obtained final equations are solved numerically on a PC with the using of own software.

\section{Results of the research}

In a first step we consider the physical process of impact interaction of a vibrating digging working tool with a sugar beet root during its extraction from the soil. It was found that during the forward movement and approaching of the vibrating digging working tool to the sugar beet root, as a result of vibrating of the digging shares in longitudinal vertical plane, the crushed soil particles located between shares and sugar beet root actually are not accumulated.

Therefore, the first contact of the digging shares with the side surface of sugar beet root is direct or, in extreme cases, through a sufficiently thin layer of the soil. Thus, during an approach of the vibrating shares of digging working tool occurs an impact that can be characterized by an impact pulse of considerable value.

Since impact pulse has a finite value, and it acts in a very short period of time, the impact force will has a significant value, which will greatly exceed all other forces, which will act at that moment on a sugar beet root.

Taking into account the fact that sugar beet root is still sufficiently fixed in a soil, there is a risk of its breaking or destruction during impact (what very often happens during harvest, especially when soil is very solid and hard, having decreased soil moisture content). Let us first consider in more details some of the common position of impact interaction of tools of mechanical systems. It should be noted that in the study of impact interactions, there is often believed that the duration of the impact is equal (or close) to zero and, therefore, it is considered that the velocities of the tools that collide, are changed instantly to some finite value. 
The positions of the bodies are not changed, so the presence in the mechanical system of elastic bonds does not affect the duration of the impact. This is because the deformations of said links, during the impact, do not appear, and therefore does not occur the reaction of these links.

If there are in mechanical systems some viscous components, then during the impact, there appear responses of the relationships, however, these reactions are of finite size (since the velocity also have finite values), and therefore their pulses during the impact are equal to zero (Pogorelij and Tatjanko, 2004).

Typically, the further (after impact) the movement will be carried out in different ways, depending on the presence or absence of a viscous or elastic ties. Since, during the collision of the vibrating digging working tool on the sugar beet root in its lower part there is not loosened soil (root of the sugar beet in its lower part is actually fixed in the layer of soil). During this impact this soil plays the role of elastic or viscous buffer (depending on the soil composition and soil moisture in the soil layer).

Thus, it is clear that the harder and drier the soil is, the above statements are correct and completely adequate to the real process of impact of the digging working tool at its contact with the sugar beet root located in the soil.

And, since during the impact interaction occurs the breaking of the tail of the sugar beet root or demaging and it is the most likely, which is always the case during the real harvest, especially when the root is in the solid and dry soil. Such case of fixing of the sugar beet root in the soil should be investigated analytically.

To solve this problem, in a first step it is very necessary to develop a force scheme of the impact interaction of a vibrating digging working tool with the body of sugar beet root. It is very important to know what happens during collision of the digging working tool with the sugar beet root.

For this, we present the vibratory digging working tool in the form of two wedges (share-type digging working tool for digging of sugar the sugar beet roots consists namely of two digging planes - shares) $A_{1} B_{1} C_{1}$ and $A_{2} B_{2} C_{2}$, and each of them has in the space the slopes at an angle $\alpha, \beta, \gamma$ and which are set with respect to each other in such a a way that they form a working channel, the back of which narrows (Figure 1). These wedges oscillate in a longitudinal-vertical plane, and the direction of translational movement of vibrating digging working tool is presented by the arrow. We suppose that the sugar beet root is completely in the soil. However, in the moment of impact interaction, the soil surrounding the root has a varying degree of connection with the sugar beet root. Thus, the front ends of the digging shares (even before their plane will be in contact with the body of root) are loosening the top layer of soil from the two sides around the root. The thickness of the soil layer is determined by the depth of digging of the vibrating working tool in the soil.

Therefore, at a given depth, the connection of the sugar beet root with the soil will be more attenuated. Below a depth of digging of the working tool in the soil this relationship of the soil with the sugar beet root is unbroken and, therefore, more durable. Separation zone of said different layers of the soil on the Figure 1 is presented by a conditional (wavy) line.

We consider that the impact interaction of the sugar beet root, which is approximated by a cone-shaped body, with the surfaces of the two wedges $A_{1} B_{1} C_{1}$ and $A_{2} B_{2} C_{2}$, has symmetrical form, at the points $K_{1}$ and $K_{2}$. Moreover, the impact contact may occur, directly or through a sufficiently thin layer of soil between the surface of the wedge and sugar beet root.

For an analytical description of the impact process it is necessary to select the system of coordinate axes. We associate with vibrating digging working body the Cartesian coordinate system $O x y z$, the center $O$, which is located in the middle of the working tool of the narrowed channel of the working tool, the axis $O x$ coincides with the direction of its forward movement, the axis $\mathrm{Oz}$ direction is up, and the axis $O y$ is directed to the right side of the working tool.

We will show the forces that arise from the interaction of the vibrating digging working tool with the body of the sugar beet root (Figure 1).

From vibrating digging working tool on the sugar beet root fixed in the soil, there is transmitted the vertical disturbing force $\bar{Q}_{\text {df., }}$ which is created by digging shares, and which varies according to the harmonic law. In the analytical form the law of variation of the given disturbing force may have the following form:

$Q_{\mathrm{df} .}=H \sin (\omega t)$

where $H$ - the amplitude of the disturbing force, $\mathrm{N} ; \omega$ - frequency of the disturbing force, $\mathrm{s}^{-1}, t$ - time interval, $\mathrm{s}$.

Since the disturbing force is applied to the body of the sugar beet root from both sides, therefore on the force scheme (Figure 1) it is represented by two components $\bar{Q}_{\mathrm{df} .1}$ and $\bar{Q}_{\mathrm{df} .2}$, which are attached at points $K_{1}$ and $K_{2}$ at a distance $h$ from the surface of a unloosened soil in which the sugar beet roots are fastened by their lower part (below the depth of the digging working tool).

Due to the fact that in this case there is a symmetric interaction of vibrating digging working tool with sugar beet root, the capture of sugar beet root by digging shares is performed equally on both sides (at the points $K_{1}$ and $K_{2}$ ), and will take place the following ratio:

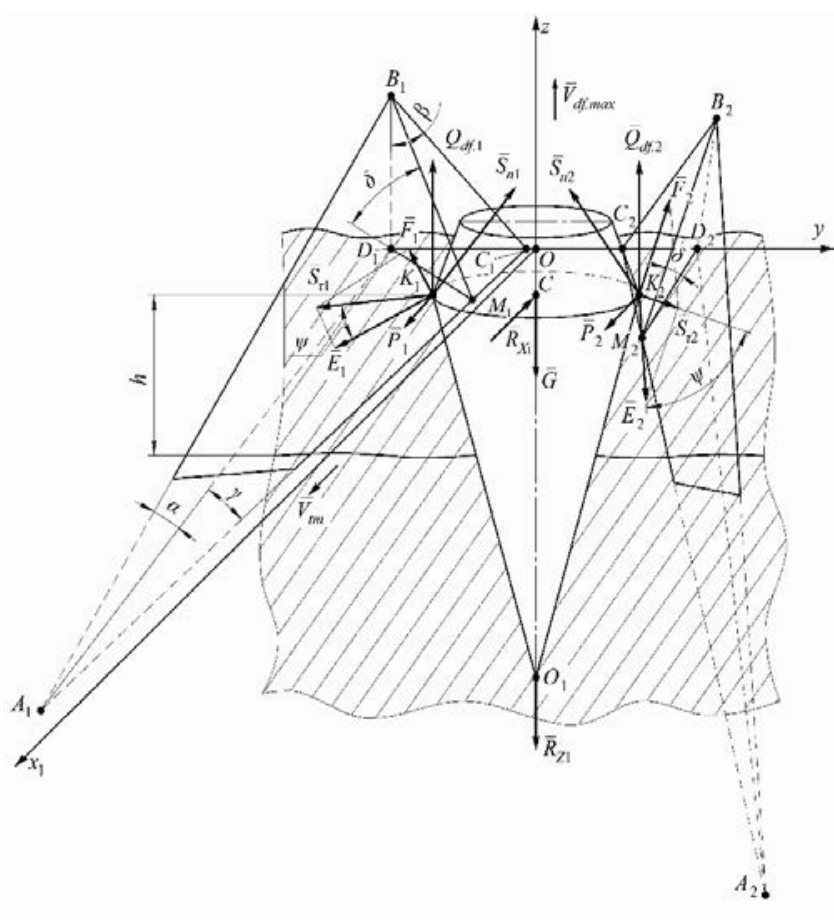

Figure 1. Force scheme of interaction of the symmetric vibrating digging working tool with the body of the sugar beet root fixed in the soil. 
$Q_{\mathrm{dfr} .1}=Q_{\mathrm{dfr} .2}=\frac{1}{2} H \sin (\omega t)$

Taking into account that vibrating digging working tool moves progressively in direction of the axis $O x$, therefore in the direction of the $O x$ axis there are also active driving forces $\bar{P}_{1}$ and $\overline{P_{2}}$, which are also attached to the points $K_{1}$ and $K_{2}$.

In addition, in points of contact $K_{1}$ and $K_{2}$, there are frictional forces $\bar{F}_{k 1}$ and $\bar{F}_{k 2}$ acting to oppose of the slipping of sugar beet root on the working surfaces of the wedges $A_{1} B_{1} C_{1}$ and $A_{2} B_{2} C_{2}$ of the digging working tool (on the scheme of Figure 1, not shown). In the center of gravity of the sugar beet root (point $C$ ) there is acting the weight force of the sugar beet root $\bar{G}_{k}$.

Forces causing the connection of the sugar beet root with the soil in the direction of $O x$ and $O z$ axes are denoted by $\bar{R}_{x}$ and $\bar{R}_{z}$ and, respectively. And finally, during the impact on the sugar beet root crop from the side of the vibrating digging working tool there are acting impact pulses $\overline{S_{n 1}}$ and $\overline{S_{n 2}}$, which are also applied at the points $K_{1}$ and $K_{2}$, and in the symmetric interaction takes place also the ratio: $S_{n 1}=S_{n 2}$. These shock pulses $\overline{S_{n 1}}$ and $\overline{S_{n 2}}$ are directed along the normals to the surfaces of shares, it means in normal direction to the planes $A_{1} B_{1} C_{1}$ and $A_{2} B_{2} C_{2}$ respectively.

Furthermore, the tangential impact pulses $\overline{S_{\tau 1}}$ and $\overline{S_{\tau 2}}\left(S_{\tau 1}=\right.$ $S_{\tau 2}$ ) act on the wedge surfaces. According to the Rous hypothesis, the relationship between the quantities of the tangent and normal impact pulses is formulated similarly to Coulomb law of friction, and namely (Panovko, 1985):

$S_{\tau} \leq f S_{n}$

where $f$ - dynamic coefficient which characterizes the properties of the surfaces of bodies that collide (in general, this ratio can be different from the coefficient of friction in the case of the relative unseparated slippage of the bodies). The inequality sign refers to the case when the tangential momentum is so small that there is no slippage of the bodies. And only in the case of slippage of the bodies in this relation should be taken an equal sign.

We factorize (decompose) the tangential impact pulses $\overline{S_{\tau 1}}$ and $\overline{S_{\tau 2}}$ on components $\overline{F_{1}}$ and $\overline{F_{2}}$, perpendicular to the lines $A_{1} C_{1}$ and $A_{2} C_{2}$ respectively, and components $\bar{E}_{1}$ and $\bar{E}_{2}$, which are parallel to lines $A_{1} C_{1}$ and $A_{2} C_{2}$, also respectively (Figure 1).

Thus, we obtain an expression for the tangential impact pulses:

$\bar{S}_{r i}=\bar{F}_{i}+\bar{E}_{i},(i=1,2)$

Further, it is obvious that the angle $\psi$ between the component $\bar{E}_{i}$ and the vector $\bar{S}_{t i}(i=1,2)$, in a first approximation depends on the ratio $V_{d f \text { max }} / V_{p}$. In the given equation $V_{d f \text { max }}$ - maximum speed of vertical displacement of the vibrating excavating tool in oscillatory motion, $\mathrm{m} \cdot \mathrm{s}^{-1} ; V_{p}$ - speed of translational movement of the vibrating excavating tool, $\mathrm{m} \cdot \mathrm{s}^{-1}$.

Also, presented vectors $\overline{S_{\tau 1}}$ and $\overline{S_{\tau 2}}$ allowed subsequently to find their projections on the axis $O x$ and $O y$.

Since the vibrating digging working tool simultaneously moves forward in the direction of the $O x$ axis and oscillates in the direction of the $O z$ axis, it is quite obvious that the impact pulses and $\overline{S_{n}}$ and $\overline{S_{n}}$ can always be decomposed into components along the axes $O x$ and $O z$. It is also quite obvious that the shock pulse component along the $O x$ axis during impact contact for any root will be the same as the speed of translational motion of the digging working tool is constant.

The component of the impact pulse on $\mathrm{Oz}$ axis can have different value depending on the speed of oscillation of the vibrating digging working tool in the vertical plane. Furthermore, since the sugar beet root has a conical shape, then during motion of the vibratory digging working tool in downward direction, the vertical component of the impact pulse will actually absent. In this case, the impact pulse will occur only during the forward speed of the digging working body.

Let us examine in more detail the vibration motion of the vibrating working tool. We assume here that vibrating working tool first moves up from its lower position " $a$ " to its top position " $a$ " (where $a$ - the amplitude of the vertical working tool vibrations), and then, on the contrary, moves down from its top position " $a$ " to lower position " $-a$ ". Thus, the vibrations of the vibrations of the vibrating digging working tool should be carried out according to the following harmonic law:

$z_{k}=-a \cos (\omega t)$

where $z_{k}$ - working body deviation vibrating digging working organ from the horizontal axis about which the oscillations are carried out, $\mathrm{m} ; \omega$ - the rotary frequency of oscillation of the working tool, $\mathrm{s}^{-1}, a$ - amplitude of vertical vibrations of the vibratory excavating tool, $\mathrm{m}$.

Then, the linear velocity $V_{d f}$ of the vibrational motion of the vibrating digging working tool at any time $t$ is equal to:

$V_{d f}=a \omega \sin (\omega t)$

and maximal value of the given velocity is equal to:

$V_{d f \cdot \max }=a \omega$

Thus, it is necessary to examine analytically such case of the impact interaction, when impact impulse will have a maximum value. This is exactly the case when at the moment of collision of the vibrating digging working tool on the sugar beet root, both its shares will be moving up to a maximum vertical speed $V_{d f \text { max }}$.

Since all the forces, that are shown on Figure 1, have a finite value, in the moment of impact, the impulses from all of these forces must be equal to zero. Only impact impulses $S_{n 1}$ and $S_{n 2}$ have a nonzero value, it is obvious that $S_{n 1}=S_{n 2}$ (the impact is symmetrical).

For next investigation we accept the theory related to changes of the motion during an impact (Panovko, 1990):

$$
m(\bar{U}-\bar{V})=\bar{S}_{n 1}+\bar{S}_{n 2}+\bar{S}_{\tau 1}+\bar{S}_{\tau 2}
$$

where $\bar{V}$ - total velocity of the vibrating digging working tool before an impact, $\mathrm{m} \cdot \mathrm{s}^{-1} ; \bar{U}$ - velocity of the digging working tool after an impact, $\mathrm{m} \cdot \mathrm{s}^{-1}$; - weight of the working organ related to the point of impact, $\mathrm{kg}$.

In such case:

$$
\bar{V}=\bar{V}_{p}+\bar{V}_{d f \max }
$$

where $\bar{V}_{p}$ - forward velocity of the motion of the vibraqting digging working tool; $\bar{V}_{d f \text { max }}$ - maximal oscilation velocity of the working tool. 
Vector translational speed $\bar{V}_{p}$ - of the digging working tool is directed along the $O x$ axis and the velocity vector of the vibrational motion of the working tool $\bar{V}_{d f \text {.max }}$ - according to the the $\mathrm{Oz}$ axis upwards. Taking into account (3), the vector equation (8) will be as follows:

$$
m(\bar{U}-\bar{V})=\bar{S}_{n 1}+\bar{S}_{n 2}+f \bar{S}_{n 1}+f \bar{S}_{n 2}
$$

We write the vector equation (10) in the projections on the axes of the Cartesian coordinate system Oxyz.

As the impact, in this case, is in fact symmetrical about a plane $x O z$, the vector equation (10) is reduced to a system of two equations - in projections onto the axis $O x$ and $O z$.

We define the necessary projection of the vectors that go into the equation (10).

It is obvious that:

$$
V_{x}=V_{p}
$$

Since the vectors $\overline{S_{n}}$ and $\overline{S_{n}}$ are directed along the normal to the surface of the wedges, according to Bulgakov and Golovach (2007), we obtain:

$$
S_{n 1 x}=S_{n 2 x}=\frac{S_{n 1} \cdot \operatorname{tg} \gamma}{\sqrt{\operatorname{tg}^{2} \gamma+1+\operatorname{tg}^{2} \beta}}
$$

As it can be seen from Figure 1, projections of the vectors $\bar{E}_{1}$, $\bar{E}_{2}$, and $\bar{F}_{1}, \bar{F}_{2}$, on the axis will be equal to:

$$
\begin{aligned}
& E_{1 x}=E_{2 x}=E_{1} \cos \gamma=\mathrm{S}_{\tau 1} \cos \psi \cdot \cos \gamma \\
& F_{1 x}=F_{2 x}=F_{1} \cos \delta \cdot \sin \gamma=S_{\tau 1} \sin \psi \cdot \cos \delta \cdot \sin \gamma
\end{aligned}
$$

It is obvious also, that:

$$
V_{z}=V_{d f \cdot \max }
$$

According to Bulgakov and Golovach (2002) we have:

$$
S_{n 1 z}=S_{n 2 z}=\frac{S_{n 1} \cdot \operatorname{tg} \beta}{\sqrt{\operatorname{tg}^{2} \gamma+1+\operatorname{tg}^{2} \beta}}
$$

Besides,

$E_{1 z}=E_{2 z}=0$

$F_{1 z}=F_{2 \mathrm{z}}=F_{1} \sin \delta=S_{\tau 1} \sin \psi \cdot \sin \delta$

With respect to equations (11)-(18), vector equation (10) is leading to the following system of equations:

$$
\left.\begin{array}{l}
m\left(U_{x}-V_{p}\right)=\frac{2 S_{n 1} \cdot \operatorname{tg} \gamma}{\sqrt{\operatorname{tg}^{2} \gamma+1+\operatorname{tg}^{2} \beta}}+2 f S_{n 1} \cos \psi \cdot \cos \gamma-2 f S_{n 1} \sin \psi \cdot \cos \delta \cdot \sin \gamma \\
m\left(U_{z}-V_{d f \cdot \max }\right)=\frac{2 S_{n 1} \cdot \operatorname{tg} \beta}{\sqrt{\operatorname{tg}^{2} \gamma+1+\operatorname{tg}^{2} \beta}}+2 f S_{n 1} \sin \psi \cdot \sin \delta
\end{array}\right\}
$$

Thus, we have obtained a system of two equations with three unknowns $S_{n 1}, U_{x}$ and $U_{z}$. To solve the problem, it is necessary to have the third equation which can be obtained by using Newton's hypothesis about the collision of two bodies (Butenin et al., 1985).

Thus, the relationship between the speed of the working tool after the impact and before the impact can be expressed by using of the coefficient of restitution $\varepsilon$ of the velocity during an impact, namely:

$U_{n}=-\varepsilon V_{n}$

where $U_{n}$ - projection of the velocity of the working tool after the impact on the surface of the wedge; $V_{n}$ - projection of the velocity of the working tool before the impact on the surface of the wedge.

$$
\text { As: }
$$

$\bar{U}=\bar{U}_{x}+\bar{U}_{z}$

$\bar{V}=\bar{V}_{p}+\bar{V}_{d f \max }$

when taking into the account (Bulgakov and Golovach, 2002), we obtain:

$$
\begin{aligned}
& U_{n}=\frac{U_{x} \cdot \operatorname{tg} \gamma+U_{z} \cdot \operatorname{tg} \beta}{\sqrt{\operatorname{tg}^{2} \gamma+1+\operatorname{tg}^{2} \beta}} \\
& V_{n}=\frac{V_{p} \cdot \operatorname{tg} \gamma+V_{d f, \max } \cdot \operatorname{tg} \beta}{\sqrt{\operatorname{tg}^{2} \gamma+1+\operatorname{tg}^{2} \beta}}
\end{aligned}
$$

By using of equations (21) and (22) in (20), we obtain the required third equation:

$U_{x} \cdot \operatorname{tg} \gamma+U_{z} \cdot \operatorname{tg} \beta=-\varepsilon\left(V_{p} \cdot \operatorname{tg} \gamma+V_{d f \cdot \max } \cdot \operatorname{tg} \beta\right)$

Thus, we finally have a system of three equations of the following form:

$$
\begin{aligned}
& m\left(U_{x}-V_{p}\right)=\frac{2 S_{n 1} \cdot \operatorname{tg} \gamma}{\sqrt{\operatorname{tg}^{2} \gamma+1+\operatorname{tg} \beta}}+2 f S_{n 1} \cos \psi \cdot \cos \gamma-2 f S_{n 1} \sin \psi \cdot \cos \delta \cdot \sin \gamma \\
& m\left(U_{x}-V_{d f \cdot \max }\right)=\frac{2 S_{n 1} \cdot \operatorname{tg} \beta}{\sqrt{\operatorname{tg}^{2} \gamma+1+\operatorname{tg}^{2} \beta}}+2 f S_{n 1} \sin \psi \cdot \sin \delta \\
& U_{x} \cdot \operatorname{tg} \gamma+U_{x} \cdot \operatorname{tg} \beta=-\varepsilon\left(V_{p} \cdot \operatorname{tg} \gamma+V_{d f \cdot \max } \cdot \operatorname{tg} \beta\right)
\end{aligned}
$$

We write the system of equations (24) in a form suitable for solution by Cramer method:

$$
\left.\begin{array}{l}
m U_{x}+0 \cdot U_{z}-\left(\frac{2 \operatorname{tg} \gamma}{\sqrt{\operatorname{tg}^{2} \gamma+1+\operatorname{tg}^{2} \beta}}+2 f \cos \psi \cdot \cos \gamma-2 f \sin \psi \cdot \cos \delta \cdot \sin \gamma\right) S_{n 1}=m V_{p} \\
0 \cdot U_{x}+m U_{x}-\left(\frac{2 \operatorname{tg} \beta}{\sqrt{\operatorname{tg}^{2} \gamma+1+\operatorname{tg}^{2} \beta}}+2 f \sin \psi \cdot \sin \delta\right) S_{n 1}=m V_{d f \cdot \max } \\
\operatorname{tg} \gamma \cdot U_{x}+\operatorname{tg} \beta \cdot U_{x}+0 \cdot S_{n 1}=-\delta\left(V_{p} \cdot \operatorname{tg} \gamma+V_{d f \cdot \max } \cdot \operatorname{tg} \beta\right)
\end{array}\right\}
$$

We can write the main determinant of the system of equations (25) and calculate its value. We obtain: 


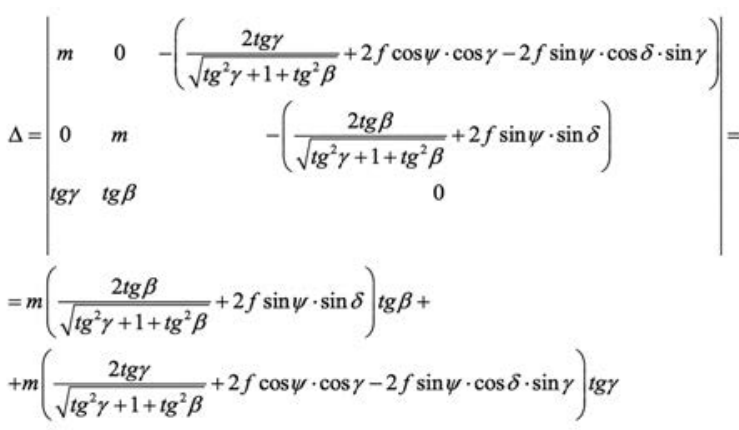

We write the determinant for a finding of the unknown $S_{n 1}$ and calculate its value. It will be equal to:

$$
\begin{aligned}
\Delta_{S n 1} & =\left|\begin{array}{ccc}
m & 0 & m V_{p} \\
0 & m & m V_{d f \text { max }} \\
\operatorname{tg} \gamma & \operatorname{tg} \beta & -\varepsilon\left(V_{p} \cdot \operatorname{tg} \gamma+V_{d f \cdot \max } \cdot \operatorname{tg} \beta\right)
\end{array}\right|= \\
& =-\left[m^{2} \varepsilon\left(V_{p} \cdot \operatorname{tg} \gamma+V_{d f, \max } \cdot \operatorname{tg} \beta\right)+m^{2} \cdot \operatorname{tg} \beta \cdot V_{d f \cdot \max }\right]-m^{2} \cdot V_{p} \cdot \operatorname{tg} \gamma
\end{aligned}
$$

In such case, according to Cramer method:

$$
S_{n 1}=\frac{\Delta_{S_{n 1}}}{\Delta}
$$

After substituing (26) and (27) into equation (28) and after some transformations we obtain:

$$
\begin{aligned}
S_{n 1}= & -\frac{m(1+\varepsilon)\left(V_{p} \cdot \operatorname{tg} \gamma+V_{d f \cdot \max } \cdot \operatorname{tg} \beta\right) \times}{2 \operatorname{tg}^{2} \beta+2 f \sin \psi \cdot \sin \delta \cdot \operatorname{tg} \beta \sqrt{\operatorname{tg}^{2} \gamma+1+\operatorname{tg}^{2} \beta}+2 \operatorname{tg}^{2} \gamma+} \times \\
& \times \frac{\times \sqrt{\operatorname{tg}^{2} \gamma+1+\operatorname{tg}^{2} \beta}}{+(2 f \cos \psi \cdot \cos \gamma-2 f \sin \psi \cdot \cos \delta \cdot \sin \gamma) \operatorname{tg} \gamma \sqrt{\operatorname{tg}^{2} \gamma+1+\operatorname{tg}^{2} \beta}}
\end{aligned}
$$

Thus, there was defined the normal component of the defined impact pulse, that occurs during the impact interaction of one of digging wedges of the vibrating working tool with the sugar beet root, fixed in soil. Expression (29) describes the functional dependence of the normal component $S_{n 1}$ of a impact pulse on the structural and kinematic parameters of vibrating digging working tool of the sugar beet harvest machine.

The sign "-" in the expression (29) means that the impuls pulse $S_{n 1}$ acts from the on the side of sugar beet root on the working tool. Impact pulse that acts from the side of the working tool on the root, has a positive sign and the same magnitude.

If we denote the total impact impulse, which acts from the side of the digging working tool on the sugar beet root (simultaneously from both digging planes) as a $\bar{S}$, that is:

$$
\bar{S}=\bar{S}_{n 1}+\bar{S}_{n 2}+\bar{S}_{\tau 1}+\bar{S}_{\tau 2}
$$

then, as can be seen from equations (19), that its projection on the $O x$ axis and $O z$ respectively, will be equal to:

$$
S_{x}=\frac{2 S_{n 1} \cdot \operatorname{tg} \gamma}{\sqrt{\operatorname{tg}^{2} \gamma+1+\operatorname{tg}^{2} \beta}}+2 f S_{n 1} \cos \psi \cdot \cos \gamma-2 f S_{n 1} \sin \psi \cdot \cos \delta \cdot \sin \gamma
$$

$S_{z}=\frac{2 S_{n 1} \cdot \operatorname{tg} \beta}{\sqrt{\operatorname{tg}^{2} \gamma+1+\operatorname{tg}^{2} \beta}}+2 f S_{n 1} \cdot \sin \psi \cdot \sin \delta$

where $S_{n 1}$ is determined according to equation (29), and definitely with the positive sign.

Thus, on the basis of expressions (31), (32) and (29) we can determine the total impact pulse which acts on the sugar beet root from the side of vibrating digging working tool:

$S=\sqrt{S_{x}^{2}+S_{z}^{2}}$

It is obvious that vector $\bar{S}$ lies in the plane $x O z$, and in the same plane are located also its projections $S_{x}$ and $S_{z}$.

However, the greatest value represents the magnitude of the impact force, rather than the impact impulse, as most indicators of physical and mechanical properties of sugar beet roots are connected with the forces which act on the sugar beet root from the side of the digging working tool.

As a rule, the unknown is a law of change of the impact force, but anyway we know that this force can be increased in a very short period of time $t_{b}$ from zero value to a maximum value and then decreases again to zero value. Obviously, the maximum impact force is approximately twice as large, compared to its average value is the time interval $t_{b}$ (Bulgakov et al., 2015d). Because the:

$S=F_{b . a v} \cdot t_{b}$

where $S$ - impact impulse, $F_{b . a v}$ - average value of the impact force, $t_{b}$. - time duration of the impact, and then:

$$
F_{b . a v .}=\frac{S}{t_{b .}}
$$

So,

$F_{b .}=2 F_{b . a v}=\frac{2 S}{t_{b .}}$

where $F_{b}$. - maximal value of the impact force.

Taking into account the equations (31), (32) and (34), we can write the projection of the force respectively on the axis $O x$ and $\mathrm{Oz}$ :

$F_{b . x}=\left(\frac{4 \operatorname{tg} \gamma}{\sqrt{\operatorname{tg}^{2} \gamma+1+\operatorname{tg}^{2} \beta}}+4 f \cos \psi \cdot \cos \gamma-4 f \sin \psi \cdot \cos \delta \cdot \sin \gamma\right) \frac{S_{n 1}}{t_{b .}}$

$F_{b . z}=\left(\frac{4 \operatorname{tg} \beta}{\sqrt{\operatorname{tg}^{2} \gamma+1+\operatorname{tg}^{2} \beta}}+4 f \sin \psi \cdot \sin \delta\right) \frac{S_{n 1}}{t_{b .}}$

where the value of $S_{n 1}$ is determined according to equation (29), taken with the positive sign.

The duration of the impact $t_{b}$ can be determined only experimentally. According to Ivanov et al. (2011) $t_{b}$. $\approx 0.60 \cdot 10^{-2} \mathrm{sec}$.

In the next step we will study the conditions how not damage the sugar beet root during its interaction during with the digging working tool.

If we consider the sugar beet root, fixed in the soil, as a cantilever beam, then under the influence of the moment from the 
strike force $\bar{F}_{b . x}$ the sugar beet root accept a bending deformation, and under the action of impact force $\bar{F}_{b . z}$ - tension deformation. Therefore, in excess of permissible values of said forces, the sugar beet root may break or it will break apart. This, as noted above, most likely, when the soil is hard and dry. If the soil is moist and soft, it is most probable that the sugar beet root will slope at an angle to the horizon under the action of horizontal force and digging of the beet root from the soil under the action of vertical force. If the impact is performed at the points $K_{1}$ and $K_{2}$ which are located at a distance $h$ from the surface of the un-loosend soil (Figure 1), the moment of the horizontal component of the impact force relative to the surface will be equal to:

$$
M_{o 1}\left(\bar{F}_{b, x}\right)=F_{b, x} \cdot h
$$

or, taking into account the equation (35):

$$
M_{o 1}\left(F_{b, x}\right)=\left(\frac{4 \operatorname{tg} \gamma}{\sqrt{\operatorname{tg}^{2} \gamma+1+\operatorname{tg}^{2} \beta}}+4 f \cos \psi \cdot \cos \gamma-4 f \sin \psi \cdot \cos \delta \cdot \sin \gamma\right) \frac{S_{n} h}{t_{b .}}
$$

When considering the conditions when the sugar beet root is not the breaking due to the influence of horizontal force $\overline{F_{b}}$. there exist theoretically two possibilities:

a) first case:

$\left[M_{b . m .}\right]<M_{m . r}$.

b) second case:

$\left[M_{b . m .}\right]>M_{m . r}$.

where $\left[M_{b . m}\right.$. $]$ - permissible bending moment for a body of root, in which there is no breaking of sugar beet root; $M_{m . r}$ - moment of resistance of the un-loosened soil in which the sugar beet root is fixed.

Because of the conditions of equilibrium there always can be valid the equation:

$$
M_{m . r .}=M_{o 1}\left(\bar{F}_{b . x}\right)
$$

in these and in further inequalities the $M_{m . r}$ should be understood as a maximal (potential) moment of resistance, which can provide a connectivity, it means, soil, in which there is fixed sugar beet root, without breaking this connectivity.

The first case is typical for dry and solid soil, the second case - for wet and soft soil.

In the first case, the breaking of sugar beet root will is possible under the following condition:

$$
\left[M_{b . m .}\right]<M_{o 1}\left(\bar{F}_{b . x}\right) \leq M_{m . r}
$$

or, considering the equation (37):

$$
\left[M_{b . . m}\right]<\left(\frac{4 \operatorname{tg} \gamma}{\sqrt{\operatorname{tg}^{2} \gamma+1+\operatorname{tg}^{2} \beta}}+4 f \cos \psi \cdot \cos \gamma-4 f \sin \psi \cdot \cos \delta \cdot \sin \gamma\right) \frac{S_{n n} h}{t_{b .}} \leq M_{m, \cdot}
$$

For the first case as a condition for not breaking the sugar beet root can be accepted:
$M_{o 1}\left(\bar{F}_{b . x}\right) \leq\left[M_{b, m .}\right]<M_{m, r .}$

or, considering the equation (37):

$\left(\frac{4 \operatorname{tg} \gamma}{\sqrt{\operatorname{tg}^{2} \gamma+1+\operatorname{tg}^{2} \beta}}+4 f \cos \psi \cdot \cos \gamma-4 f \sin \psi \cdot \cos \delta \cdot \sin \gamma\right) \frac{S_{n} h}{t_{b .}} \leq\left[M_{\text {b.... }}\right]<M_{m . r .}$

In the second case, the breaking of the sugar beet root is generally unlikely, since it would be possible the tilt of it at a certain angle.

It is obvious that the condition of a tilt of the sugar beet root without destruction in this case will has the following form:

$$
M_{m . r .}<M_{o 1}\left(\bar{F}_{b . x}\right)<\left[M_{b, m .}\right]
$$

or, considering the equation (37):

$$
M_{m, r}<\left(\frac{4 \operatorname{tg} \gamma}{\sqrt{\operatorname{tg}^{2} \gamma+1+\operatorname{tg}^{2} \beta}}+4 f \cos \psi \cdot \cos \gamma-4 f \sin \psi \cdot \cos \delta \cdot \sin \gamma\right) \frac{S_{m} h}{t_{b .}}<\left[M_{b . . .}\right]
$$

Finally, in the second case, the root will have no tilt and destruction will not occure in the following conditon:

$$
M_{o 1}\left(\bar{F}_{b . x}\right) \leq M_{m . r .}<\left[M_{b . m .}\right]
$$

or, considering the equation (37):

$$
\left(\frac{4 \operatorname{tg} \gamma}{\sqrt{\operatorname{tg}^{2} \gamma+1+\operatorname{tg}^{2} \beta}}+4 f \cos \psi \cdot \cos \gamma-4 f \sin \psi \cdot \cos \delta \cdot \sin \gamma\right) \frac{S_{n t^{\prime}} h}{t_{b .}} \leq M_{m,-,}<\left[M_{b, \ldots}\right]
$$

When considering the conditions for no destruction of the sugar beet root under the vertical impact force there also theoretically can exist two possibilities:

a) first case:

$\left[F_{q .}\right]<R_{z}$

b) second case:

$\left[F_{q .}\right]>R_{z}$

where $\left[F_{q}\right]$ - the force permissible for the body of the sugar beet root, when the root destruction does not occure; $R_{z}$ - vertical force of the connection of a sugar beet root with the soil.

Under the $R_{z}$ it is necessary to understand such maximal (potential) connection force, which can provide connection, without destroying this connection.

The first case is typical for dry and solid soil, the second case - for wet and soft soil.

In first case the destruction of the sugar beet root can occure in the following conditions:

$\left[F_{q .}\right]<F_{b . z} \leq R_{z}$

or, considering the equation (36): 


$$
\left[F_{q}\right]<\left(\frac{4 \operatorname{tg} \beta}{\sqrt{\operatorname{tg}^{2} \gamma+1+\operatorname{tg}^{2} \beta}}+4 f \sin \psi \cdot \sin \delta\right) \frac{S_{n 1}}{t_{b .}} \leq R_{z}
$$

For the first case the destruction of the sugar beet root will not occure in the following conditions:

$F_{b . z} \leq\left[F_{q .}\right]<R_{z}$,

or, considering the equation (36):

$\left(\frac{4 \operatorname{tg} \beta}{\sqrt{\operatorname{tg}^{2} \gamma+1+\operatorname{tg}^{2} \beta}}+4 f \sin \psi \cdot \sin \delta\right) \frac{S_{n 1}}{t_{b .}} \leq\left[F_{q}\right]<R_{x}$

In the second case, the destruction of the sugar beet root is unlikely. There may occure the digging of the sugar beet root from the soil without breaking.

The digging of the sugar beet root out from the soil will be possible in the following condition:

$R_{z}<F_{b . z}<\left[F_{q .}\right]$

or, considering the equation (36):

$$
R_{s}<\left(\frac{4 \operatorname{tg} \beta}{\sqrt{\operatorname{tg}^{2} \gamma+1+\operatorname{tg}^{2} \beta}}+4 f \sin \psi \cdot \sin \delta\right) \frac{S_{n 1}}{t_{b .}}<\left[F_{q}\right]
$$

In the following condition there will be impossible to provide digging of the sugar beet root out from the soil:

$F_{b . z} \leq R_{z}<\left[F_{q .}\right]$

or, considering the equation (36):

$\left(\frac{4 \operatorname{tg} \beta}{\sqrt{\operatorname{tg}^{2} \gamma+1+\operatorname{tg}^{2} \beta}}+4 f \sin \psi \cdot \sin \delta\right) \frac{S_{n 1}}{t_{b .}} \leq R_{z}<\left[F_{q}\right]$

From the condition of not breaking of sugar beet root (39) and the conditions of no destruction (43) for impact interaction of the digging working tool with sugar beet root we define the limits on the speed of forward movement of the digging working tool. Based on this aim from the equation (39) we find:

$$
S_{n 1} \leq \frac{\left[M_{b, .}\right] t_{b,} \cdot \sqrt{\operatorname{tg}^{2} \gamma+1+\operatorname{tg}^{2} \beta}}{h\left[4 \operatorname{tg} \gamma+(4 f \cos \psi \cdot \cos \gamma-4 f \sin \psi \cdot \cos \delta \cdot \sin \gamma) \sqrt{\operatorname{tg}^{2} \gamma+1+\operatorname{tg}^{2} \beta}\right]}
$$

and from equation (43) we find:

$$
S_{n 1} \leq \frac{\left[F_{q}\right] t_{\mathrm{b}} \cdot \sqrt{\operatorname{tg}^{2} \gamma+1+\operatorname{tg}^{2} \beta}}{4 \operatorname{tg} \beta+4 f \sin \psi \cdot \sin \delta \sqrt{\operatorname{tg}^{2} \gamma+1+\operatorname{tg}^{2} \beta}}
$$

For convenience and shortening of the notation of the anothers equations we introduce the following indication:

$\sqrt{\operatorname{tg}^{2} \gamma+1+\operatorname{tg}^{2} \beta}$

$4 \operatorname{tg} \gamma+(4 f \cos \psi \cdot \cos \gamma-4 f \sin \psi \cdot \cos \delta \cdot \sin \gamma) \sqrt{\operatorname{tg}^{2} \gamma+1+\operatorname{tg}^{2} \beta}$ $\frac{\sqrt{\operatorname{tg}^{2} \gamma+1+\operatorname{tg}^{2} \beta}}{4 \operatorname{tg} \beta+4 f \sin \psi \cdot \sin \delta \sqrt{\operatorname{tg}^{2} \gamma+1+\operatorname{tg}^{2} \beta}}=B$

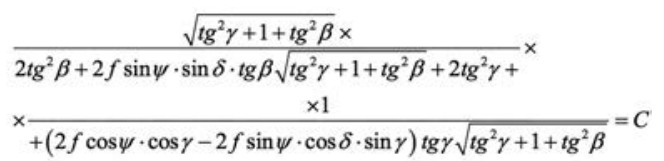

In such case the equations (29), (46) and (47) respectively, will have the following form:

$S_{n 1}=C_{m}(1+\varepsilon) \cdot\left(V_{p} \cdot \operatorname{tg} \gamma+V_{d f \cdot \max } \cdot \operatorname{tg} \beta\right)$

$S_{n 1} \leq \frac{A\left[M_{b . m .}\right] t_{b .}}{h}$

$S_{n 1} \leq B\left[F_{q}\right] t_{b}$

where the equation (29) was taken with the positive sign.

Thus, the two expressions are obtained for limiting the impact impulse $S_{n 1}$, namely (52) and (53). In this case, the breakage of the root as the cantilever beam is most likely on the border of the loosened and un-loosened layer of the soil, where the tail of the root is fixed. The breakage of the tail section of sugar beet root beet, having a sectional diameter of $30-40 \mathrm{~cm}$ corresponds to the depth of the motion of the of the vibrating digging working tool in the soil, which is $10-12 \mathrm{~cm}$. It is obvious that in this section of root breakage due its bending is more likely than its breakage due to dilatation (breakage caused by dilatation can occure in the lower part of the root below this section, where there is a much smaller diameter of the root). Therefore, for the measure for the evaluation of the permissible impact pulse we accept the expression (52). Though theoretically the permissible impact pulse $S_{n 1}$ should be determined by a such criteria:

$$
S_{n 1} \leq \min \left\{\frac{A\left[M_{b, m}\right] t_{b .}}{h}, B\left[F_{q .}\right] t_{b .}\right\}
$$

However, in accordance with the above reasoning, for a particular cross section, it follows that:

$\min \left\{\frac{A\left[M_{b . . .}\right] t_{b b}}{h}, B\left[F_{q}.\right] t_{b .}\right\}=\frac{A\left[M_{b . . .}\right] t_{b .}}{h}$

From the equation (51) we determine:

$V_{p} \cdot \operatorname{tg} \gamma+V_{d f \cdot \max } \cdot \operatorname{tg} \beta=\frac{S_{n 1}}{C m(1+\varepsilon)}$

Finally, taking into account (54), we obtain the following inequality:

$V_{p} \cdot \operatorname{tg} \gamma+V_{d f \cdot \max } \cdot \operatorname{tg} \beta \leq \frac{A\left[M_{b . m .}\right] t_{b .}}{C m(1+\varepsilon) h}$ 
Thus, there were determined the constraints concerning the speed of the vibrating digging working tool, with regard of its design parameters and weights, as well as the strength of the sugar beet root and the coefficient of the recovery rate during an impact.

As the speed of the digging working tool (the forward speed of the sugar beet harvester) affects its performance, then we will study the case when the equation (56) will contain a sign of equality. If in the first step there is entered the forward speed $V_{p}$ of the movement of digging working tool (sugar beet harvester), then from equation (56) we find the value of the maximum speed $V_{d f \text {.max }}$ of the vibrational motion of the vibrating digging working tool:

$$
V_{d f \cdot \max }=\frac{1}{\operatorname{tg} \beta}\left(\frac{A\left[M_{b \cdot m .}\right] t_{b+}}{C m(1+\varepsilon) h}-V_{p} \cdot \operatorname{tg} \gamma\right)
$$

Then from the expression (7) there can be found, for a given amplitude, the desired circular frequency of the vibrations of the digging working tool from the conditions not to damage a sugar beet root:

$$
\omega=\frac{1}{a \cdot \operatorname{tg} \beta}\left(\frac{A\left[M_{b, m .}\right] t_{b .}}{C m(1+\varepsilon) h}-V_{p} \cdot \operatorname{tg} \gamma\right)
$$

The frequency of the vibrations of the digging-working tool, expressed in $\mathrm{Hz}$, will be equal to:

$$
v=\frac{1}{2 \pi a \cdot \operatorname{tg} \beta}\left(\frac{A\left[M_{b, m .}\right] t_{b .}}{C m(1+\varepsilon) h}-V_{p} \cdot \operatorname{tg} \gamma\right)
$$

Further, on the basis of the theory developed, we construct the algorithm for calculating of the permissible frequency $v$ of vibrations of the vibrating digging working tool in relation to the speed of its forward movement $V_{p}$, and the amplitude $a$ of oscillations at different depths $h$ when moving in the soil.

To perform the calculations you must, first of all, input the values of some parameters, which are included in the expression (59).

First of all, we will ipnut the parameters of triangular wedges of the vibrating working tool, namely the corners and (Figure 1). According to the design documentation for vibratory digging working tools we will consider that values of these angles will be equal to: $\gamma=14^{\circ}-15^{\circ}, \beta=50^{\circ}-55^{\circ}$. To determine the two-edged angle $\delta$ between the working surface and a lower wedge base using expression (Pogorelij and Tatjanko, 2004):

$$
\delta=\operatorname{arctg} \frac{\cos \beta}{\sin \beta \cdot \cos \gamma}
$$

The dynamic coefficient of friction of the steel on the surface of the root we accept according to Bulgakov and Golovach (2004): $f=0.45$. The angle $\psi=45^{\circ}$ responds to its average value. The distance from the point $K_{1}$ of the impact contact up to the bottom edge of the wedge (but actually up to not loosened soil) $h=0.05 \mathrm{~m}$. We consider that the value of the coefficient of recovery during impact is equal to $\varepsilon=0.72$, which we determined experimentally.

The permissible bending moment $\left[M_{b . m}\right.$. $]$ can be determined by the same way. If we assume that $z$ - the depth of motion of the vibrating digging working tool in the soil, it is obvious that the most likely is the break of the root body at this depth, because at the depth deeper than the $z$, the root body is located in more dense soil, not loosened soil and at a depth of less than $z$, the cross section of the root is larger, since the root body has a conical shape. At the same time, the cross-sectional diameter $d_{k}$ of the beet root body at a depth $z$ will be determined on the basis of this expression:

$d_{k}=D_{k}-2 z \cdot \operatorname{tg} \gamma_{k}$

where $D_{k}$ - diameter of the sugar beet root, $\mathrm{m}, \gamma_{k}$ - cone angle, grad.

Then, as we know from the course of Strength of Materials, the permissible bending moment of the conical body of the sugar beet root is:

$$
\left[M_{b, m .}\right]=[\sigma]_{\partial} \cdot \frac{\pi d_{k}^{3}}{32}
$$

where $[\sigma] \partial$ - temporary resistance of the bending of sugar beet root due to the dynamic load, Pa.

Taking into accoun the above mentioned equation we obtain the value $\left[M_{b . m .}\right]$ :

$$
\left[M_{b, m,}\right]=[\sigma]_{0} \cdot \frac{\pi\left(D_{k}-2 z \cdot \operatorname{tg} \gamma_{k}\right)^{3}}{32}
$$

According to Bulgakov and Golovach (2004): $D_{k}=67-122 \mathrm{~mm}$ (we use $D_{k}=100 \mathrm{~mm}$ ); $\gamma_{k}=9^{\circ}-18^{\circ}\left(\right.$ we use $\left.\gamma_{k}=15^{\circ}\right) ;[\sigma]_{\partial}=1.15 \cdot 10^{6}$ $\mathrm{Pa}$.

Next, we must determine the mass of the working tool, acting on the point of impact. Indicative set of given mass values can be determined using the expression (59), inputing the intervals and amplitudes of vibration frequencies of digging working tool as well as the speed of its forward movement (these data can be taken from the results of experimental studies). Then, the value of the acting mass $m$, obtained as a function $m=m\left(v, V_{p}\right)$ of the vibration frequency $v$ of the digging working tool and the speed $V_{p}$ of its forward movement, shall be equal to $m=0.8-1.5 \mathrm{~kg}$.

The values of the coefficients $A$ and $C$ can be determined according to equations (48) and (50).

In the next step, for the individual values of parametres we determine the permissible value of the vibration frequency $v$ of the digging working tool as a function $v=v\left(V_{p}, a\right)$, for the conditions not to break the body of the sugar beet root. According to the own PC software there were performed calculations, which had allowed to prepare the graphs and a contour graphs (Figure 2) expressing the permissible values of the vibration frequency $v$ for the given mass $m=0.8-1.5 \mathrm{~kg}$ and depth $h=0.08-0.10 \mathrm{~m}$ of movement of the vibrating digging working tool in the soil (Figures 2-7). It should be noted that the permissible frequencies must be limited from above to a value of $2.0 \mathrm{~Hz}$, which is determined by the reliability of the operation of the drive of the vibratory digging tool into the vibrational motion.

As it can be seen from the graphs (Figures 2-7), while increasing the speed of translational motion and vibration amplitude of the vibrating digging working tool, the values of the permissible oscillation frequency are decreasing. The trend towards a decrease in the permissible frequency of oscillations can also be seen with increasing of the depth of movement of the vibrating digging working tool in the soil.

Numerical calculations performed on a PC made it possible to recommend the permissible values of the oscillation frequencies of 
the vibrating digging working tool for the conditions not to break the tail section of sugar beet root during an impact interaction and for conditions of compulsory capture of each root by working tool within the forward speed range of motion of $1.3-2.2 \mathrm{~m} \cdot \mathrm{s}^{-1}$, the used mass of the digging working tool $m=0.8 ; 1.0 ; 1.5 ; 2.0 \mathrm{~kg}$, depth of the motion in the soil $z=0.08 ; 0.1 ; 0.12 ; 0.14 \mathrm{~m}$, and the oscillation amplitude $a=0.008-0.024 \mathrm{~m}$, which are presented in Table 1 .

To carry out experimental studies of the process of vibrational
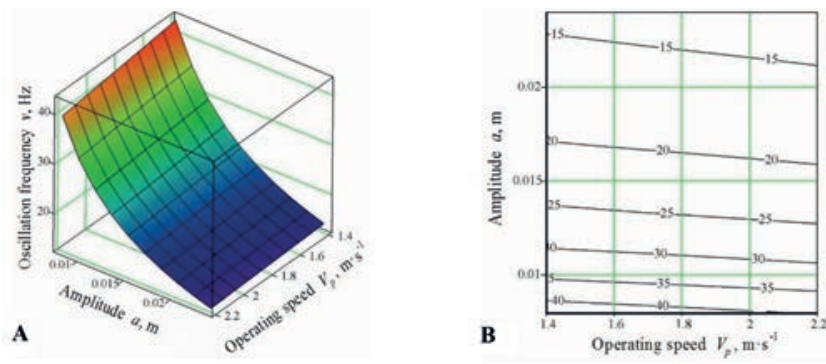

Figure 2. A) The surface and B) a contour graph of the permissible values the oscillation frequency of the vibrating digging working tool $v=v\left(V_{p}, a\right), \mathrm{Hz}$, depending on the different speed of motion and the amplitude of the oscillations: the reduced mass is $0.8 \mathrm{~kg}$; motion in the soil depth $-0.08 \mathrm{~m}$.
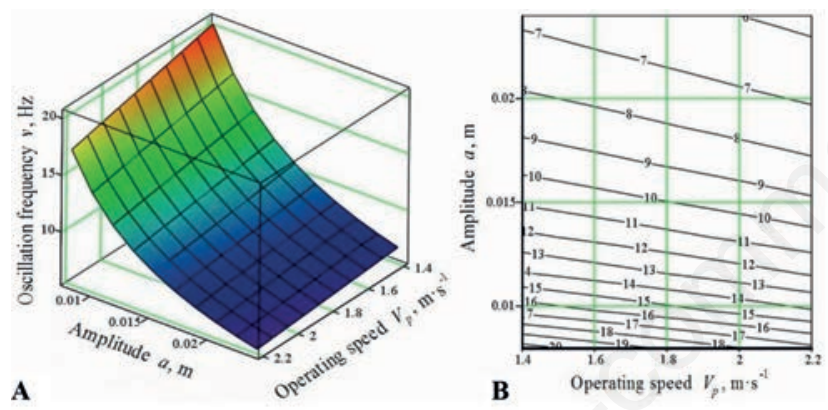

Figure 3. A) The surface and B) a contour graph of the permissible values the oscillation frequency of the vibrating digging working tool $v=v\left(V_{p}, a\right), \mathrm{Hz}$, depending on the different speed of motion and the amplitude of the oscillations: the reduced mass is $0.8 \mathrm{~kg}$; motion in the soil depth $-0.10 \mathrm{~m}$.
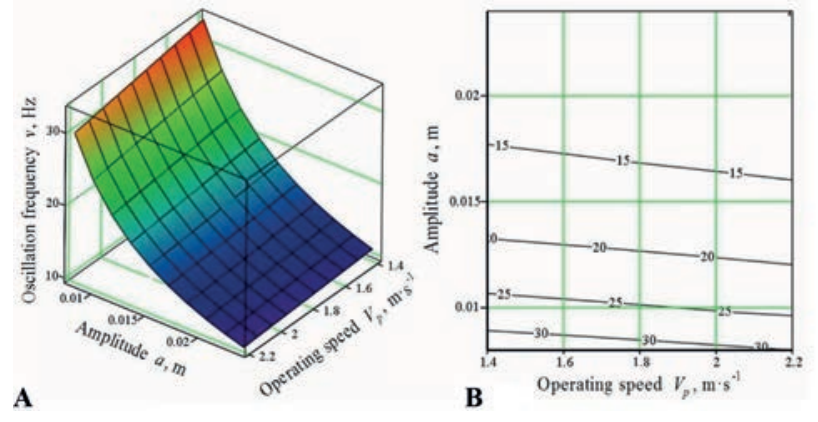

Figure 4. A) The surface and B) a contour graph of the permissible values the oscillation frequency of the vibrating digging working tool $v=v\left(V_{p}, a\right), \mathrm{Hz}$, depending on the different speed of motion and the amplitude of the oscillations: the reduced mass is $1.0 \mathrm{~kg}$; motion in the soil depth $-0.08 \mathrm{~m}$. digging out of sugar beet roots from the soil and to study the shock interaction of scraping coulombs (planes) with the sugar beet root body, a new design of the vibratory digger was designed and fabricated (Bulgakov and Golovach, 2007), a design and technological scheme and a general view of which are presented on Figure 8.

At the same time, the basic constructive and kinematic parameters that were obtained during the theoretical studies were used in the construction of this vibratory digging working body. At the
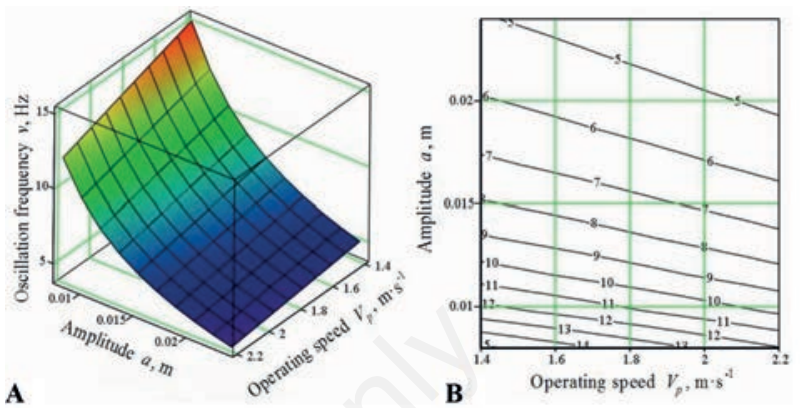

Figure 5. A) The surface and B) a contour graph of the permissible values the oscillation frequency of the vibrating digging working tool $v=v\left(V_{p}, a\right), \mathrm{Hz}$, depending on the different speed of motion and the amplitude of the oscillations: the reduced mass is $1.0 \mathrm{~kg}$; motion in the soil depth $-0.10 \mathrm{~m}$.
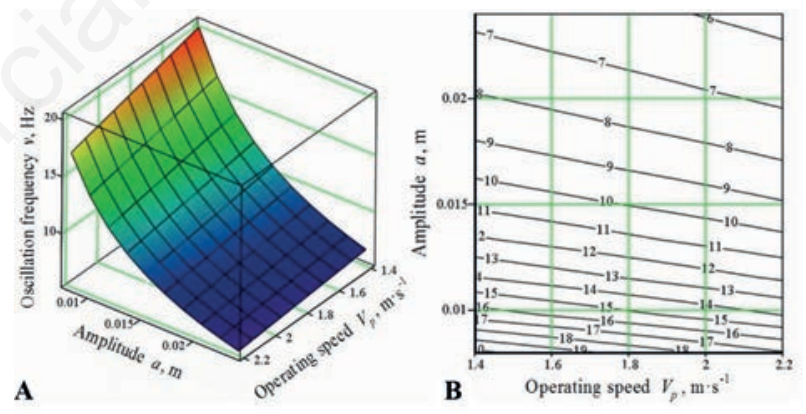

Figure 6. A) The surface and B) a contour graph of the permissible values the oscillation frequency of the vibrating digging working tool $v=v\left(V_{p}, a\right), \mathrm{Hz}$, depending on the different speed of motion and the amplitude of the oscillations: the reduced mass is $1.5 \mathrm{~kg}$; motion in the soil depth $-0.08 \mathrm{~m}$.
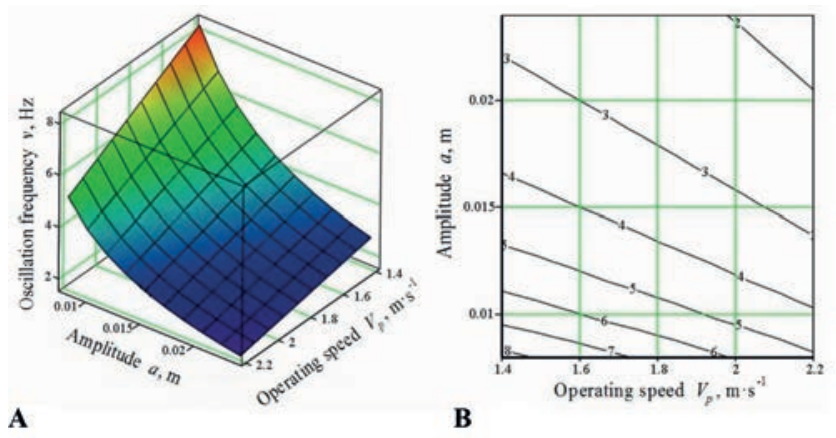

Figure 7. A) The surface and B) a contour graph of the permissible values the oscillation frequency of the vibrating digging working tool $v=v\left(V_{p}, a\right), \mathrm{Hz}$, depending on the different speed of motion and the amplitude of the oscillations: the reduced mass is $1.5 \mathrm{~kg}$; motion in the soil depth $-0.10 \mathrm{~m}$. 
same time, carrying out experimental studies and comprehensive tests of this new vibratory digging working organ was aimed at ensuring the intactness of sugar beet roots from the soil under various parameters of the oscillatory process, and inadmissibility of their losses, provided that the working organ strikes against the body of sugar beet roots.

The vibratory digging tool of the new design consists of scraping couches (planes) that are fixed to the ends of the struts 2 , which, with the help of the brackets of the suspension 3 , are connected to the driving mechanism 4 of the coulters 1 in oscillatory movements in the longitudinal-vertical plane. The mechanism 4 has a device that can adjust the amplitude and frequency of the vibrational movements of the coulters 1 in a wide range of their values (the frequency is adjustable from 8.5 to $20.3 \mathrm{~Hz}$, the amplitude is from 8.0 to $24.0 \mathrm{~mm}$ ). In addition, the suspension bracket 3 racks 2 is equipped with an additional hinge, which allows a small range to carry out the free movement of paired racks 2 in the longitudinal-vertical plane. This ensures the self-alignment of the shares 1 with the forward movement of the digging working organ, which is not present in the existing structures of similar working organs for digging out sugar beet roots from the soil.

To carry out the experimental studies, a laboratory-field installation (Figure 9) was made in the form of a four-row sugar beet root harvesting machine, on which experimental studies of the shock interaction of scooping plowshares with root crops of sugar beet were carried out.

The experimental setup consists of a main frame 1, which rests on the bridges of the rear 2 and front 3 wheels. In this case, the wheels 3 perform the functions of copying, and the frame 1 is connected to the aggregating tractor by means of a strain gauge link. In the front part of the frame 1, vibratory digging working organs 4 of a new design there are installed, additionally equipped with beaters 5 . In general, the experimental sample of the sugar beet root harvesting machine was equipped with cleaning and transporting working elements: a paddle bitter cleaner 6 and longitudinal and unloading conveyors. The vibratory digging device 4 consists of a crank drive 7 and digging planes 8 .

During the experimental studies, the cleaning working organs were cut off from the experimental sugar beet root harvesting machine and the sugar beet roots dug from the soil were immediately laid on the film, which was unwound from a roll installed on the frame immediately behind the digging working organs.

Soil conditions of the site for the experimental study of the vibrational digging of sugar beet roots from the soil during impact interaction of digging mechanism and root crops were following: soil type - heavy loam; soil hardness - 3.8 - 4.0 MPa; soil moisture content $-8 \%$; density of plantations of root crops of sugar beet 150 thousand pieces per ha; average size of root crops: diameter $0.094 \mathrm{~m}$, length $-0.24 \mathrm{~m}$, weight $-0.9 \mathrm{~kg}$.

In Figure 10 shows photos of sugar beet roots that have been digging out from the soil by a new vibratory digging working organ.

As a result of statistical processing of the results of experimental studies, graphical dependencies of the qualitative indices of the vibrational digging of the sugar beet roots from the soil were obtained under the condition of shock contacts of digging organs and root bodies. These data are presented on Figures 11-13.

As Figure 11 shows, the loss of sugar beet roots at a vibration vibration frequency of the vibrating excavating organ from 8.0 to $22.0 \mathrm{~Hz}$ does not exceed $3.8 \%$, which fully satisfies the existing agrotechnical requirements for harvesting of the sugar beet roots.

As can be seen from the graphs obtained, the damage of the sugar beet roots due to the vibration frequencies of the vibrating digging tool is from 8.0 to $22.0 \mathrm{~Hz}$, which also satisfies the
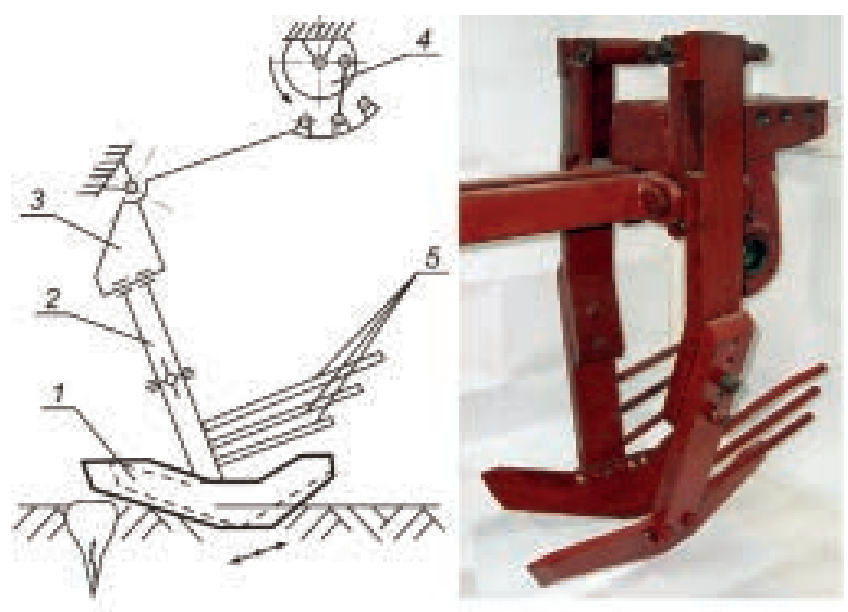

A

B

Figure 8. A new vibratory digging working organ for sugar beet roots: A) constructive technological scheme; B) general view of the working body: 1 - digging ploughshares (planes); 2 - racks; 3 - mechanism for regulating the distance between scaling planes; 4 - vibrating drive with a mechanism for adjusting the amplitude and frequency of oscillations of the digging planes; 5 - guiding fingers.

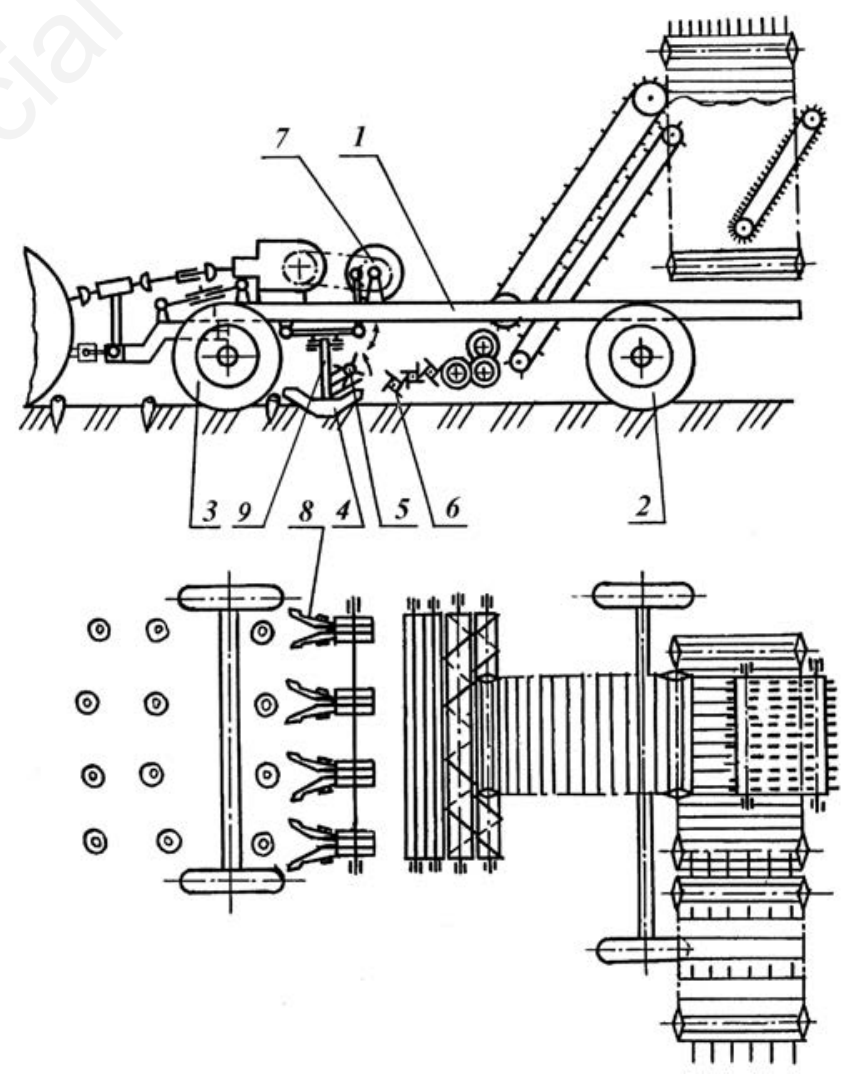

Figure 9. Scheme of an experimental sugar beet root-harvesting machine equipped with new vibrating digging organs: 1 - frame; 2 - axle of rear wheels; 3 - axle of front (copying) wheels; 4 vibratory digging working bodies; 5 - beater; 6 - four-bladed beater cleaner; 7 - crank drive of the vibratory digging working body; 8 - scooping plowshares (planes). 
existing agrotechnical requirements for harvesting of the sugar beet roots. From the graphs obtained, it can be seen that in this case (in the case of digging out the sugar beet roots from soft and moist soil), the roots damage does not exceed $6.2 \%$, which, with a significantly, meets the technical requirements for harvesting of the sugar beet roots. Based on the results of the experimental

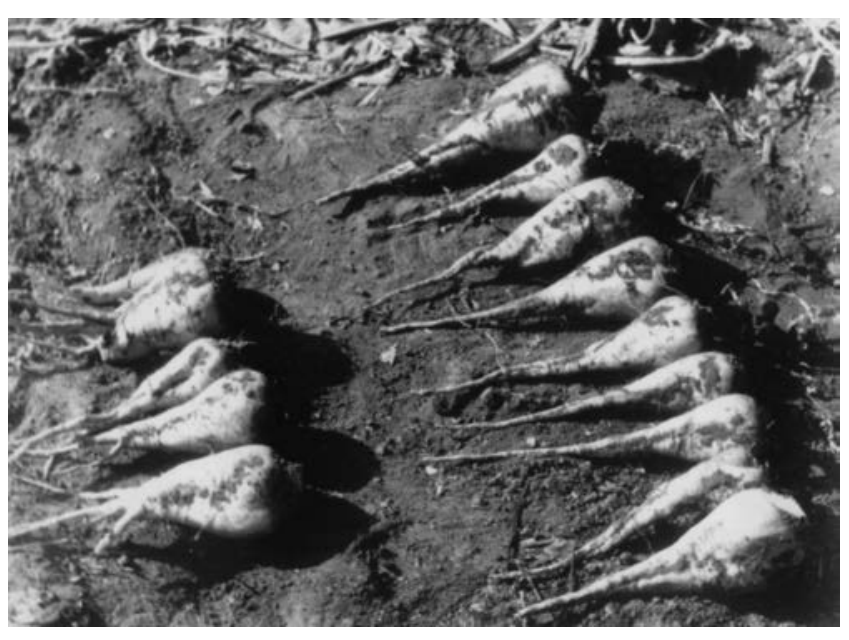

Figure 10. Sugar beet roots, dug by new vibrational digging out working bodies during experimental studies.
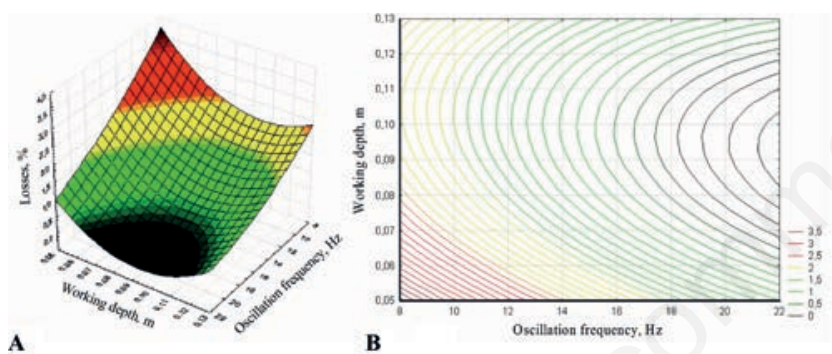

Figure 11. A) Quadratic response of the surface and B) a twodimensional cross-section of the quadratic response surface of sugar beet roots losses due to the oscillation frequency of a working organ and the depth of its course in the soil at a forward speed of $1.75 \mathrm{~m} \cdot \mathrm{s}^{-1}$, soil hardness $4.00 \mathrm{MPa}$ and soil moisture content $8 \%$
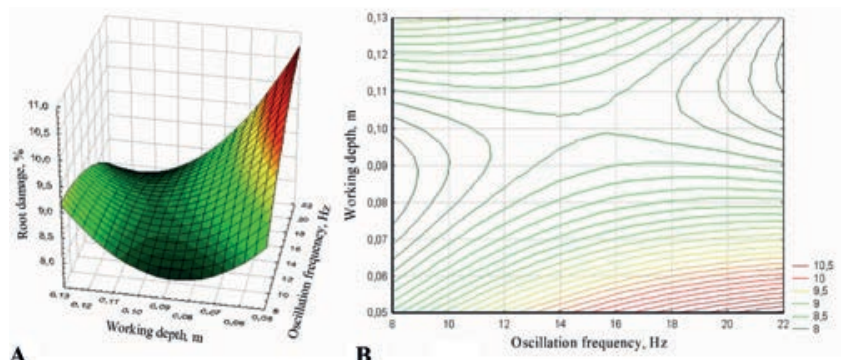

Figure 12. A) The quadratic response of the surface and $B$ ) the two-dimensional section of the quadratic response surface of the sugar beet beet root damage due to the oscillation frequency of the working organ and the depth of its course in the soil at a forward speed of $1.30 \mathrm{~m} \cdot \mathrm{s}^{-1}$, soil hardness $4.00 \mathrm{MPa}$ and soil moisture content $8 \%$ studies it has been found that it is expedient to use a design of the vibratory digging tool that would ensure that in the range of translational velocities $1.3-2.1 \mathrm{~m} \cdot \mathrm{s}^{-1}$ and the oscillation amplitude of the working element in the range $0.008-0.024 \mathrm{~m}$, vibration frequency $8-18 \mathrm{~Hz}$ and the depth of travel in the soil of digging organs (shares) $0.08-0.10 \mathrm{~m}$. The specified kinematic parameters of the work ensure high-quality performance of the technological process of vibrating digging of sugar beet roots, which satisfies the existing agrotechnical requirements regarding root losses and damage. This frequency range of oscillations of the vibratory digging working organ, which ensures the qualitative extraction of the sugar beet roots from the soil, completely coincides with the calculation calculated earlier on the basis of the developed theory and given in Table 1, which indicates the adequacy of theoretical and experimental studies.

\section{Conclusions}

There was developed a most complex theory of the impact interaction of the digging working tool with the sugar beet root, fixed in the soil.

Based on a obtained equation of the impact interaction, which acts in two points, there was determined an impact impulse and maximal impact force, which which occur at a specified impact interaction.

There was obtained an analytical expression for determining the permissible vibration frequency of the vibrating digging working tool on the basis of the conditions not to damage the beet roots with regard of its design parameters and the forward speed of the sugar beet harvester. It allows to define the desired frequency when digging sugar beet roots from the soil.

There was developed the algorithm for calculations of the permissible frequency of vibrating digging working tool, taking into account the request not to break the sugar beet roots during an impact interaction. Numerical calculations performed on a PC made it possible to recommend the permissible values of the oscillation frequencies of the vibrating digging working tool, depending on the design, kinematic and technological parameters of the process of digging, recommended values of the above parameters are presented in Table 1 .
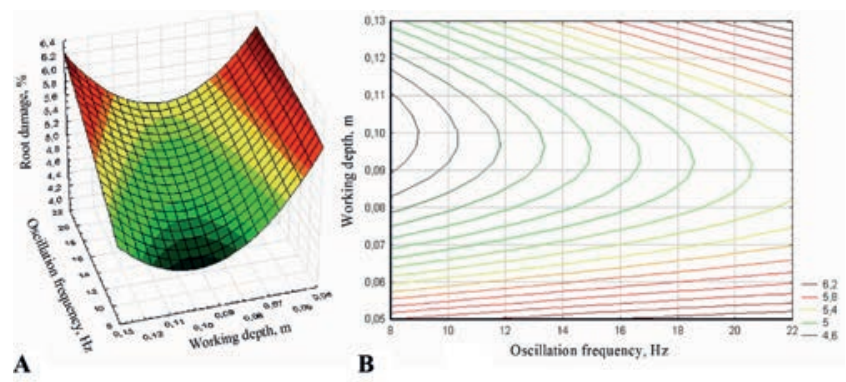

Figure 13. A) The quadratic response of the surface and B) the two-dimensional section of the quadratic response surface of the sugar beet root damage from the oscillation frequency of the working organ and the depth of its course in the soil at a forward speed of $2.55 \mathrm{~m} \cdot \mathrm{s}^{-1}$, soil hardness $2.00 \mathrm{MPa}$ and soil moisture content $18 \%$. 
Table 1. Recommended frequencies $v$ vibrations of the vibrational digging working organ, $\mathrm{Hz}$.

\begin{tabular}{|c|c|c|c|c|c|c|c|c|c|}
\hline \multirow[t]{2}{*}{$\begin{array}{l}\text { Used weight of the } \\
\text { working organ } \\
(\mathrm{m}, \mathrm{kg})\end{array}$} & & 0.08 & & $\begin{array}{l}\text { of motion of } \\
\text { Amplitu }\end{array}$ & working bod & $\begin{array}{l}\text { in the soil }(z \\
0.10 \\
(a, \mathrm{~m})\end{array}$ & m) & & 0.12 \\
\hline & $0.008-0.016$ & $0.018-0.020$ & $0.008-0.024$ & $0.008-0.024$ & $0.008-0.018$ & $0.020-0.024$ & $0.008-0.010$ & 0.012 & $0.008-0.024$ \\
\hline 0.8 & - & - & 18.0 & 10.0 & - & - & - & - & 9.0 \\
\hline 1.0 & - & - & 16.4 & - & 10.0 & 8.3 & - & - & - \\
\hline 1.5 & - & - & 10.0 & - & - & - & 10.0 & 8.0 & - \\
\hline 2.0 & 10.0 & 8.1 & - & - & - & - & - & - & - \\
\hline
\end{tabular}

Based on the results of the experimental studies it has been found that it is expedient to use a design of the vibratory digging organ that would ensure that in the range of translational velocities $1.3-2.1 \mathrm{~m} . \mathrm{s}^{-1}$ and the vibration amplitude of the vibratory digging organ in the range $0.008-0.024 \mathrm{~m}$ frequency oscillations of $10-18$ $\mathrm{Hz}$ and the depth of travel in the soil of digging organ $0.08-0.10 \mathrm{~m}$. The specified kinematic parameters of the work ensure highquality performance of the technological process of vibrating digging of sugar beet roots, which satisfies the existing agrotechnical requirements regarding losses and damage of sugar beet roots.

\section{References}

Adamchuk V.V., Bulgakov V.M. 2015. Teorija vibracionnikh vykapyvajushchikh sveklouborochnih mashin: Monografia. Agrarnaja nauka, Kiev. [In Russian].

Bulgakov V., Adamchuk V., Olt J. Orszaghova D. 2015a. Use of Euler equations in research into three-dimensional oscillations of sugar beet root during its vibration-assisted lifting. Agron. Res, 13:33-45.

Bulgakov V.M., Golovach I.V. 2002. Utochnennaja teorija vykapivajushchego rabochego organa lemeshnogo tipa//Vestnik agrarnoj nauky Prichernomorja. Specialnij vypusk 4(18). Tom I. - Nikolaev: NGAU, - p. 37-63. [In Russian].

Bulgakov V.M., Golovach I.V. 2004. Teorija poperechnih kolebanij korneploda pri vibracionnom vykapivanii. - Trudy Tavricheskoj gosudarstvennoj agrotehnicheskoj akademii. Vypusk 18. - Melitopol, - p. 8-24. [In Russian].

Bulgakov V.M., Golovach I.V. 2005. Pro vynuzhdennie poperechnie kolebanija tela korneploda pri vibracionnom vykapivanii. Vestnik Kharkovskogo nacionalnogo universietta selskogo khozjajstva imeni Petra Vasielenko: Sbornik nauchnih trudov. Vypusk 39. Kharkov: KhNTUSKh, - p. 23-39. [In Russian].

Bulgakov V.M., Golovach I.V. 2006a. Razrabotka matematicheskoj modeli izvlechenija koerneploda iz pochvy//Tekhnika APK. Kiev, No. 6, 7, 8. - p. 36-38. [In Russian].

Bulgakov V.M., Golovach I.V. 2006b. Teoreticheskoe issledovanie prodolnih kolebanij korneploda $\mathrm{v}$ pochve pri vibracinnom vykapivanii. - Vestnik Kharkovskogo nacionalnogo universietta selskogo khozjajstva imeni Petra Vasielenko: Sbornik nauchnih trudov. Vypusk 44, tom 2. Kharkov: KhNTUSKh, p. 131-155. [In Russian].
Bulgakov V.M., Golovach I.V. 2007. Patent Ukraine № 84977 , MPK A 01 D 25/04. Vibracionnij vykapyvajishchij rabochij organ/Bulgakov V.M., Golovach I.V.: Nacionalnyj agrarnyj universitet. - № a 200703858; zajavlen 06.04.2007; opublikovan 10.12.2008. Bulletin № 23. [In Russian].

Bulgakov V.M., Golovach I.V., Adamchuk V.V. 2015b. Theoretical research of the impact of the digging-out working tool on the beetroot during the vibrational digging up from the soil. Agric. Sci. Pract. 2:9-20.

Bulgakov V.M., Golovach I.V., Adamchuk V.V. 2015c. Theoretical research of the impact of the digging-out working toll on the beetroot during the vibrational digging up from the Soil. Agric. Sci. Pract. 2:9-20.

Bulgakov V., Ivanov S. 2010. Mathematical simulation of beet vibrational extraction. Engine. Rural Develop. 27-28:25-31.

Bulgakov V., Olt J., Adamchuk V., Arak M. 2015d. Theory of asymmetric impact interaction between vibrating digging tool and body of sugar beet root. Mechan. Agric. LXI:23-5.

Butenin N.V., Lunc Ja.L., Merkin D.R. 1985. Kurs teoreticheskoj mekhaniky. T.II. Dynamika. - Moskva: Nauka, - 496 pp. [In Russian].

Golovach I.V. 2006. Teorija neposredstvennogo izvlechenija korneploda iz pochvy pri vibracinnom vykapivanii. - Vestnik Kharkovskogo nacionalnogo universietta selskogo khozjajstva imeni Petra Vasielenko: Sbornik nauchnih trudov. Vypusk 44, tom 2. Kharkov: KhNTUSKh, - p. 77-100. [In Russian].

Ivanov S., Bulgakov V., Pawłowski T. 2011. Theoretical investigation of the process of digging roots vibration method. J. Res. Appl. Agric. Engine. 56:147-51.

Panovko Ja.G. 1985. Vvedenie v teoriju mekhanicheskgo udara. Moskva: Nauka, - 287 p. [In Russian].

Panovko Ja.G. 1990. Osnovy prikladnoj teorii kolebanij i udara. Leningrad: Polytekhnika, - 272 pp. [In Russian].

Pogorelij L.V., Tatjanko N.V. 1983. Sveklouborochnie mashiny (konstruirovanie i raschet) // L.V. Pogorelij, N.V. Tatjanko, V.V. Brej i dr.; pod obshchej redakciej L.V. Pogorelogo. - Kiev: Tekhnika, - 168 c. [In Russian].

Pogorelij L.V., Tatjanko N.V. 2004. Sveklouborochnie mashiny (istorija, konstrukcija, teorija, prognoz). - Kiev: Feniks, - 232 p. [In Russian].

Vasilenko P.M., Pogorelij L.V., Brej V.V. 1970. Vibracionnij sposob uborky korneplodov//Mekhanizacija i elektrifikacija socialisticheskogo selskogo khozjajstva. Moskva, No. 2 - p. 9-13. [In Russian]. 